\title{
Preface to the Special Issue on FORMOSAT-3/COSMIC Mission Early Results
}

\author{
Chio-Zong (Frank) Cheng, Ying-Hwa Kuo, and Jann-Yenq Liu
}

Citation: Cheng, C. Z., Y. H. Kuo, and J. Y. Liu, 2009: Preface to the special issue on FORMOSAT-3/COSMIC mission early results. Terr. Atmos. Ocean. Sci., 20, I-II, doi: 10.3319/TAO.2008.09.03.01(F3C)

Six identical micro-satellites comprising the FORMOSAT-3/COSMIC (Formosa Satellite \#3 and Constellation Observing System for Meteorology, Ionosphere and Climate) mission were successfully launched into a circular low-Earth orbit from Vandenberg Air Force Base, California at 0140 UTC 15 April 2006. The FORMOSAT-3/COSMIC mission is a collaborative project jointly carried out by the National Space Organization (NSPO) in Taiwan and the University Corporation for Atmospheric Research (UCAR) in USA, with the participation of many governmental, academic and private institutions. Each FORMOSAT-3 satellite carries three primary science instruments: a GPS Occultation Experiment (GOX) payload, a Tiny Ionospheric Photometer (TIP), and a Tri-Band Beacon (TBB) payload. The GOX provides vertical sounding of atmospheric profiles around the globe and electron density profiles in the ionosphere. The TIP instrument is a narrow band far-ultraviolet radiometer; it operates in the $131.0-160.0 \mathrm{~nm}$ bandwidth with a focus wavelength at $135.6 \mathrm{~nm}$ to measure the lineof-sight total electron content. The TBB transmits phase coherent, continuous signals at three frequencies: VHF (150.012 MHz), UHF (400.032 MHz), and L-band $(1066.752 \mathrm{MHz})$ to provide ionospheric observations to ground-based receivers.

The FORMOSAT-3/COSMIC mission provides the first satellite constellation for monitoring global weather and ionospheric electron density distribution using the Global Positioning System (GPS) radio occultation (RO) technique. Every day the mission provides in near-real time about 2000 vertical profiles of temperature, pressure and water vapor in the neutral atmosphere and over 2000 vertical electron density profiles in the ionosphere. The observations have been used to support operational global weather prediction, climate monitoring and research, space weather forecasting, and ionosphere and gravity research.

More than 70 papers describing early results from the mission and Intensive Observation Period (IOP) campaign were presented at the "FORMOSAT-3/COSMIC Workshop 2006: Early Results and IOP Campaign," held in Taipei during 28 Nov. - 1 Dec. 2006. The cross-validation of the FORMOSAT-3 data with other types of measurements has shown significantly greater precision than was possible with traditional methods and models. The applications of the
FORMOSAT-3 weather data have been extraordinarily successful, from predicting the typhoon track to capturing the genesis and transition of a tropical storm into a typhoon. Improvement of up to $10 \%$ in weather forecasting accuracy has been achieved using the data.

With the demonstration of real-time operational use of RO observations, FORMOSAT-3/COSMIC complements other Earth observing systems and improves global weather analyses and prediction. The success of FORMOSAT-3/ COSMIC mission inaugurates an age of operational GPS sounding for weather forecasting, climate analysis and research, ionospheric monitoring, and a suite of related earth science pursuits.

This special issue includes some of the distinguished papers presented in the "FORMOSAT-3/COSMIC Workshop 2006: Early Results and IOP Campaign." It is the first such issue in an earth science journal to publish exclusively early important results of FORMOSAT-3/COSMIC mission. This issue covers the following subjects: (1) the FORMOSAT-3/ COSMIC mission overview, satellite status and operation; (2) weather data assimilation and data impact studies; (3) IOP campaigns and data impact; and (4) ionospheric data and space weather monitoring.

The guest editors of the special issue would like to thank the authors for contributing their time and effort for this special issue. We also would like to thank the NSPO for the financial support in the publication of this issue. Finally, we would like to thank Dr. Sunny Tam and Dr. Kaiti Wang of the Plasma and Space Science Center, National Cheng Kung University, Taiwan for helping the editorial processes.

\section{Responsible Editor:}

Lin-Ni Hau

Institute of Space Science, National Central University E-mail:1nhau@jupiter.ss.ncu.edu.tw

\section{Guest Editor:}

Ying-Hwa Kuo

University Corporation for Atmospheric Research, USA

E-mail:kuo@ucar.edu 
Jann-Yenq Liu

Institute of Space Science, National Central University

E-mail: jyliu@jupiter.ss.ncu.edu.tw

\section{Executive Guest Editor:}

Chio-Zong (Frank) Cheng

Plasma and Space Science Center and Department of Physics, National Cheng Kung University

E-mail: frankcheng@pssc.ncku.edu.tw 